Research Article

\title{
Evaluation of Chinese Transport Infrastructure Investment Performance in Countries along the Belt and Road Initiative
}

\author{
Yanbin Yang, ${ }^{1}$ Wei Liu $\left(D,{ }^{1}\right.$ Kaiyuan Li, ${ }^{1}$ Yuping Jin, ${ }^{1}$ and Shijia Liang ${ }^{2}$ \\ ${ }^{1}$ College of Transport and Communications, Shanghai Maritime University, Shanghai 201306, China \\ ${ }^{2}$ School of International Education, Shanghai University of Sport, Shanghai 200438, China \\ Correspondence should be addressed to Wei Liu; weiliu@shmtu.edu.cn
}

Received 2 June 2021; Revised 22 July 2021; Accepted 31 July 2021; Published 9 August 2021

Academic Editor: Serdar Ulubeyli

Copyright (c) 2021 Yanbin Yang et al. This is an open access article distributed under the Creative Commons Attribution License, which permits unrestricted use, distribution, and reproduction in any medium, provided the original work is properly cited.

Since the launch of the Belt and Road Initiative (BRI) in 2013, Chinese enterprises have invested heavily in transport infrastructure projects. In order to better promote Chinese overseas transport infrastructure investment (TII) and avoid additional risks, it is necessary to scientifically assess the performance of Chinese TII in countries along the BRI and explore the promotion path of Chinese TII performance. For this reason, we used a superefficient slacks-based measurement (SE-SBM) model to calculate Chinese TII performance based on 5 dimensions, including political environment, economic environment, institutional environment, humanistic environment, and social environment. These 5 dimensions were divided into 14 indicators, and we used quantification with indirect data to quantify all indicators. Then, according to the performance value of selected countries, we classified them into high-, medium-, and low-performance areas. Next, combined with the scale of returns and the shadow price of input indicators, we provided the promotion measures of each performance area. Our analysis generates valuable measures to reduce TII risks and better promote the connectivity of countries along the BRI.

\section{Introduction}

The Belt and Road Initiative (BRI) put forward by China in 2013 aims to build an interconnected network through closer connectivity partnership among countries along the BRI. The initiative focuses on the communication and cooperation of politics, infrastructure, trade, finance, and people. Under the BRI, China and other countries are actively planning the construction of six economic corridors, namely, China-Mongolia-Russia Economic Corridor, New Eurasian Continental Bridge, China-Central Asia-West Asia Economic Corridor, China-Indochina Peninsula Economic Corridor, China-Pakistan Economic Corridor, and Bangladesh-China-India-Myanmar Economic Corridor. These have created opportunities for economic development in the regions and effectively promoted economy and trade between countries. In 2016, the GDP growth rate of countries and regions along the BRI was 4.6 percent, higher than the average growth rate of 3.6 percent in developing countries. However, in terms of infrastructure connectivity, Kristian points out that infrastructure construction plays a very important role in promoting countries' economic growth and regional economic integration [1]. And the backward transportation infrastructure will hamper the development of trade [2].

The transport infrastructure such as road, railway, shipping, and aviation along the BRI has developed rapidly, but the overall development level is relatively low. According to the Global Competitiveness Report (2019), the transport infrastructure index of West Asia, Southeast Asia, Central and Eastern Europe, and other regions enjoying the convenience of water transportation is significantly higher than that of inland hinterland. Except for some countries with missing data on transport infrastructure index, among the countries along the BRI, the top five countries in the index include Singapore (91.7) in Southeast Asia, United Arab Emirates (84.1), Oman (73.1), Qatar (71.4) in West Asia, and the Czech Republic in Central and Eastern Europe (70.5). The last five countries are Yemen (20.5) in West Asia, Kyrgyzstan (32.1) in Central Asia, Mongolia (35.5) in East 
Asia, and Albania (35.5) and Bosnia and Herzegovina (39.8) in Central and Eastern Europe. These index values show that transport infrastructure level of these countries is quite different, which affects the interconnection efficiency between countries to a certain extent.

Countries along the BRI vary in capital, construction capacity, and construction efficiency. Meanwhile, in order to promote the economic and trade cooperation among countries along the BRI, Chinese enterprises have invested heavily in transportation infrastructure projects. According to statistics from the Ministry of Commerce, People's Republic of China, there were 506 overseas projects contracted for more than $\$ 100$ million in 2019 alone. And most of them were hosted in countries along the BRI. At the moment, Chinese companies have carried out a lot of investment in overseas infrastructure construction and achieved some results. The construction of transport infrastructure is expected to boost intraregional trade and increase the trade quantum along the BRI by $4.1 \%$ [3]. And for those countries that do not receive Chinese direct investment, there will be more trade volume due to the enhanced connectivity, improved infrastructure along the BRI as well as better trade relationship between China and the target markets [4].

Compared with the large amount of infrastructure investment made by Chinese companies, the study on how to avoid additional risks in investment in the field of transportation is less rational. At the same time, due to the high sunk cost, ongoing debt crisis, and irreversible and nontradable characteristics of transport infrastructure, transport infrastructure investment (TII) will inevitably take a variety of potential risks, which will be more aggravated under the background of the BRI. Faced with many problems and challenges, if the TII performance of these countries can be evaluated scientifically and comprehensively based on data and we can discover and solve the existing problems in the TII and cooperative development, it will undoubtedly help to enhance the courage and confidence in the future construction of the BRI.

The main purpose of this study is to scientifically assess the performance of Chinese TII in countries along the Belt and Road Initiative and explore the promotion path of Chinese TII performance. Empirically, we analyzed the factors affecting TII cooperation between China and countries along the BRI using the approach proposed by Zhou et al. [5]. Based on superefficient slacks-based measurement (SE-SBM) model, this study evaluated the TII performance of these countries. Then, we categorized these countries based on the performance value and analyzed Chinese investment propensity. Eventually, considering the return to scale analysis and shadow prices of all indicators, the promotion paths were proposed.

The structure of this paper is as follows. Section 2 summarizes the existing literature. Section 3 introduces research methods. Section 4 constructs TII evaluation index system and collected relevant data. In Section 5, we calculate and analyze TII performance and shadow price. Section 6 provides promotion path in different performance areas. Finally, the conclusions and implications are provided in Section 7 .

\section{Literature Review}

After the announcement of the BRI, Chinese overseas investment increased significantly, and state-owned enterprises invested more in infrastructure than private ones [6]. The impact analysis of infrastructure investment on regional development is a research focus at present. Roland-Holst pointed out that there is an obvious structural Keynesian multiplier effect in infrastructure investment, indicating that through the supply chain, infrastructure investment can not only promote finance, research, and sales, but also boost the growth of products and services [7]. Improvement in transportation infrastructure can reduce transportation costs [8]. Decrease in transportation cost will affect the flow of commodity and regional differences in economic growth, which is influenced by "price index effect" and "domestic market effect" [9]. Moreover, transportation infrastructure is cointegrated with foreign direct investment and economic growth, which shows that there is a long-term equilibrium relationship between them [10]. In terms of the impact of specific transportation infrastructure investment, Anas et al. measured the potential economic revenues to the regional economy of transportation project investment [11]. The authors pointed out that the project would reduce transportation costs and that the regional economy would increase by $1 \%$. Xu analyzed the impact of the railway project on China's cargo exports to Central Asia. The results showed that the value of freight exports increased by about $30 \%$ after the railway upgrade [12]. Investment in transportation infrastructure not only has a positive economic effect on the places where it is invested, but also promotes their economy, welfare, employment, and foreign trade to varying degrees due to the more convenient connection with other regions [13]. For instance, Ahlfeldt and Feddersen studied the agglomeration economic effects of high-speed rail on cities along the routes and their neighboring cities [14]. However, this investment in transportation infrastructure cannot promote economic growth in the short term; instead, its economic diffusion effect will gradually accelerate in the long term [15].

In addition, investment in transportation infrastructure will also lead to a substantial increase in energy consumption and the output of energy-intensive industries [16]. Ji et al. estimated that the investment projects of China were up to 4.7 trillion RMB, and found that the investment plan would increase the national energy consumption by about $3 \%$ per year from 2016 to 2018 [17].

Some scholars have further studied the factors affecting transportation infrastructure investment. Foreign trade is highly correlated with the transportation industry. Good transportation infrastructure can provide convenience for foreign trade business, and the continuous development of trade also stimulates the continuous improvement of transportation infrastructure [18]. The same is true for international tourism communication [19]. To a certain extent, the technical and informatization level of a country also reflects the demand for external investment [20]. Government laws, regulations, and policies play an important supporting role in guiding and supporting Chinese outward foreign direct investment (OFDI). According to the study of Yin et al., the best 
policy means to support OFDI is to relax regulatory policy and introduce supervision and service policies [21]. Moreover, investment in transport infrastructure involves the government's decision-making on large, complicated projects with uncertain standards, which is extremely susceptible to government corruption [22, 23]. Considering tangibility and visibility of transportation investment, politicians participating in the election may be influenced by politics, and thus their investment efficiency is not optimal [24]. Furthermore, poor governance will also affect transportation investment in the planning and project selection stage.

These factors can explain the change of investment efficiency [25] so that the direction of improvement can be found. Kyriacou et al. did so by way of DEA and evaluated the capacity of countries to achieve the maximum amount and utilization of infrastructure at a given scale of investment [26]. Marchetti and Wanke evaluated the efficiency of Brazilian railway concessionaires using DEA, analyzed the reasons for the change in efficiency according to various variables (the main types of goods transported like agriculture, minerals, or others), and used two-stage analysis to find out the factors that might promote the efficiency [27]. Liu et al. studied the antecedent variables of China's OFDI along the BRI, showing that the location choice of China's OFDI was influenced by exchange rate, market potential, openness, and infrastructure. This result also has confirmed that China's investment is not resource-driven [28]. $\mathrm{Zu}$ and Liu came up with similar conclusions, demonstrating that China's OFDI is insensitive to exchange rate and political situation [29]. Taking the transportation infrastructure investment of Chinese enterprises in countries along the BRI as an empirical background, Chen et al. studied the antecedent variables of transportation infrastructure investment, which provides a reference for enterprises to make investment decisions [30].

Chinese companies have carried out a lot of investment in overseas transport infrastructure construction, which will result in a more mature transport network and a more prosperous interregional trade. The extant literature mainly studies the effect of transportation infrastructure investment on the investment places and surrounding areas, and there are many evaluations and location choices for specific investment projects. However, there is a lack of evaluation research on the macro TII performance, especially the research on the promotion path of TII performance. Therefore, this paper will use the superefficient slacks-based measurement model to evaluate the performance of TII in countries along the BRI and analyze its promotion path, so as to discover the investment potential.

\section{Research Methods}

Tone put forward SBM (slack-based measurement), a model based on slack variables, which directly added slack variables to the objective function [31]. It is assumed that there are $n$ decision-making units (DMU) in the production system, each of which has input and output indexes. These two index matrices are expressed as $X=\left(x_{i j}\right) \in R^{m * n}$ and
$Y=\left(y_{r j}\right) \in R^{s * n}$, where $x_{i j}$ and $y_{r j}$ represent input iand output $r$ of $\mathrm{DMU}_{j}$, respectively, and $i=1, \cdots, m ; r=1, \cdots$, $s ; j=1, \cdots, n$. Define production possibility set $P$

$$
P=\{(x, y) \vee x \geq X \lambda, y \leq Y \lambda, \lambda \geq 0\} .
$$

Assuming that decision unit $o$ is evaluated and recorded asDMU ${ }_{o}$, decision-making unit $\left(x_{o}, y_{o}\right)$ is expressed as

$$
\begin{aligned}
& x_{o}=X \lambda+S^{-}, \\
& y_{o}=Y \lambda-S^{+},
\end{aligned}
$$

where $\lambda \geq 0, S^{-} \geq 0$, and $S^{+} \geq 0$, which, respectively, represent input redundancy and output shortage, that is, the slack of input and output. SBM model uses $\rho^{*}\left(0 \leq \rho^{*} \leq 1\right)$ to express the efficiency value of DMU to be evaluated. Tone put forward SBM model as

$$
\begin{gathered}
\rho^{*}=\min \frac{1-(1 / m) \sum_{i=1}^{m}\left(S_{i}^{-} / x_{i o}\right)}{1+(1 / S) \sum_{r=1}^{S}\left(S_{r}^{+} / y_{r o}\right)}, \\
\text { S.T. }\left\{\begin{array}{l}
x_{o}=X \lambda+S^{-}, \\
y_{o}=Y \lambda-S^{+}, \\
\lambda \geq 0, S^{-} \geq 0, S^{+} \geq 0 .
\end{array}\right.
\end{gathered}
$$

As the highest efficiency value measured by SBM model is 1 , and it is impossible to further compare the effective decision-making units, the method of measuring efficiency by SBM model can no longer meet the current research needs. In order to solve this question, Tone improved the original SBM model and put forward the superefficient slacks-based measurement (SE-SBM) model to evaluate the effective decision-making units of SBM, so that the efficiency values of all decision-making units could be calculated [31]. Under the premise that $\mathrm{DMU}_{o}$ is effective, the point $\left(x_{o}, y_{o}\right)$ is removed from $(X, Y)$, and the production possibility set $P$ is expressed by mathematical formula as follows:

$$
\frac{P}{\left(x_{o}, y_{o}\right)}=\{(\bar{x}, \bar{y}) \mid \bar{x} \geq X \lambda, \bar{y} \leq Y \lambda, \bar{y} \geq 0, \lambda \geq 0\} .
$$

Meanwhile, $\bar{P} /\left(x_{o}, y_{o}\right)$ is defined as a subset of $P /\left(x_{o}, y_{o}\right)$. Suppose that $X>0, \lambda>0, \bar{P} /\left(x_{0}, y_{o}\right)$ and $P /\left(x_{o}, y_{o}\right)$ is not empty.

$$
\frac{\bar{P}}{\left(x_{o}, y_{o}\right)}=\frac{P}{\left(x_{o}, y_{o}\right)} \cap\left\{\bar{x} \geq x_{o} \text { and } \bar{y} \leq y_{o}\right\} .
$$

Then, the superefficient SBM model is

$$
\delta^{*}=\min \frac{(1 / m) \sum_{i=1}^{m}\left(\bar{x} / x_{i o}\right)}{(1 / S) \sum_{r=1}^{S}\left(\bar{y} / y_{r o}\right)}
$$

$$
\text { S.T. }\left\{\begin{array}{l}
\bar{x} \geq X \lambda, \\
\bar{y} \leq Y \lambda, \\
\bar{x} \geq x_{o} \text { and } \bar{y} \leq y_{o}, \\
\lambda>0 .
\end{array}\right.
$$


The dual program of problem (6) can be expressed as follows, with the dual variables $\xi \in R^{m}, v \in R^{m}$, and $u \in R^{S}$. Maximize $\xi$,

$$
\text { S.T. }\left\{\begin{array}{l}
\xi+v x_{o}-u y_{o}=1, \\
u Y-v X \leq 0, \\
v \geq \frac{1}{m}\left[\frac{1}{x_{o}}\right], \\
u \geq \frac{\xi}{S}\left[\frac{1}{y_{o}}\right],
\end{array}\right.
$$

where $\left[1 / x_{o}\right]$ represents the vector $\left(\left(1 / x_{1 o}\right),\left(1 / x_{2 o}\right)\right.$, $\left.\left(1 / x_{m o}\right)\right)$. In this dual model, the resource valuation is represented as the shadow price of the corresponding input indicators.

The economic meaning of shadow price $x_{i}$ of index $i$ is the marginal profit when the index $i$ increases. To put it simply, $x_{i}$ is the increment of the final objective function (Chinese TII performance) for each unit value of the index $i$ increased. It is worth noting that the shadow price of the same input varies from country to country. In this way, we can evaluate the importance of index $i$ to Chinese TII performance by observing the value of $x_{i}$, which is also an important reference for improving Chinese TII performance in the target country.

\section{Construction of the Evaluation System and Data Collection}

4.1. Construction of the Evaluation System. By analyzing the influencing factors in the literature and the availability of data, we constructed the transport infrastructure investment evaluation system along the BRI. At first, China's outward FDI stock in transport was selected as the output indicator by country and region. Secondly, based on the existing literature [32-47], we selected 5 first-level indicators and 14 second-level indicators. The first-level indicators were, respectively, political environment, economic environment, institutional environment, humanistic environment, and social environment. Thirdly, the second-level indicators was either measured directly from the report or calculated by existing data. The measurement and data source of each indicator are shown in Table 1.

4.2. Data Collection. Our observation period, which starts in 2011 and ends in 2019, can reflect the differences and trends before and after the implementation of the BRI. Our research covers 65 countries along the BRI [30]. These data are from the data source in Table 1 . However, due to the lack of data, we excluded 17 countries. In the end, we chose 48 countries for our study.

\section{Analysis of TII Performance and Shadow Price}

5.1. Analysis of TII Performance. SBM and SE-SBM were, respectively, used to evaluate the performance of Chinese TII in countries along the BRI from 2011 to 2019. And we used DEA-Solver 5.0 for calculation. The TII performance value of target countries and their ranking in 2019 are shown in Table 2. It can be seen from the table that when the TII performance value is less than 1, the evaluation results of SBM model and superefficient SBM model are the same. However, the maximum performance evaluation value of SBM model is 1 , which makes it impossible for many countries with the TII performance value of 1 to determine their ranking. By contrast, the maximum performance evaluation value of SE-SBM model is not limited to 1 , indicating that it can rank countries with DEA effectiveness.

In 2019, Chinese TII performance in Singapore, Iran, Indonesia, the United Arab Emirates, Iraq, Bangladesh, Pakistan, Kuwait, and Yemen was DEA effective. And there are significant differences among countries within each region.

In order to further analyze the promotion path of Chinese TII performance along the BRI, we classified the average TII performance of 48 countries along the BRI from 2011 to 2019 through cluster analysis using SPSS software and sum of squares of deviations. Then, 48 countries were divided into three categories: high-investment performance area, medium-investment performance area, and low-investment performance area. Table 3 shows the specific classification results.

5.2. Analysis of Shadow Price. The shadow price of input indicators in all countries has a certain trend from 2011 to 2019. By calculating the shadow price, we found that among the input indicators with the largest shadow price in all countries, the three input indicators with the largest proportion were $\times 4$ (openness), $\times 6$ (trade relations with China), and $\times 11$ (cultural communication), respectively (as shown in Figure 1). The most important factor for China to invest in transportation infrastructure along the BRI was $\times 6$. There is also a trend among these factors that the number of countries with $\times 6$ as the most influential factor peaked in 2012 and 2013 and then reduced gradually. Instead, $\times 4$ began to increase. In 2013, when China proposed the BRI, Chinese TII performance was most affected by the trade relations between target country and China. And the improvement of transportation infrastructure quality of target countries could increase the trade between China and target countries. As time goes by, the BRI has been accepted by more and more countries, and they have begun to actively support Chinese investment, which also makes China start to pay more attention to the openness of each country. Eventually, the interconnection among countries will also help facilitate the global trade. This is also the original intention of the BRI. Due to the large proportion of $\times 4$ and $\times 6$, these two factors will not be analyzed in the subsequent promotion path. 
TABLE 1: Transport infrastructure investment evaluation system along the BRI.

\begin{tabular}{|c|c|c|c|c|}
\hline Catalog & $\begin{array}{l}\text { First-level } \\
\text { indicators }\end{array}$ & Second-level indicators & Measurement & Data source \\
\hline \multirow{15}{*}{ Input } & & $\begin{array}{l}\text { Government stability } \\
\qquad(\times 1)\end{array}$ & Government stability from ICRG & PSR group \\
\hline & $\begin{array}{c}\text { Political } \\
\text { environment }\end{array}$ & $\begin{array}{l}\text { Political relations with } \\
\text { China }(\times 2)\end{array}$ & $\begin{array}{c}\text { Number of years that diplomatic relations with } \\
\text { China }\end{array}$ & Government website \\
\hline & \multirow{6}{*}{$\begin{array}{l}\text { Economic } \\
\text { environment }\end{array}$} & Military in stability $(\times 3)$ & Military in stability from ICRG & PSR Group \\
\hline & & Openness $(\times 4)$ & $\begin{array}{c}\text { The proportion of a country's imports and exports } \\
\text { to GDP }\end{array}$ & $\begin{array}{c}\text { Calculated by data of World } \\
\text { Bank }\end{array}$ \\
\hline & & Economic freedom $(\times 5)$ & Economic freedom index & Heritage Foundation \\
\hline & & Trade relations with & The proportion of imports and exports between & Calculated by data of World \\
\hline & & China $(\times 6)$ & $\begin{array}{l}\text { the country and China in the country's total } \\
\text { imports and exports }\end{array}$ & $\begin{array}{c}\text { Bank and China Statistical } \\
\text { Yearbook }\end{array}$ \\
\hline & & Monetary freedom $(\times 7)$ & Risk for inflation from ICRG & PSR Group \\
\hline & \multirow{2}{*}{$\begin{array}{l}\text { Institutional } \\
\text { environment }\end{array}$} & $\begin{array}{l}\text { Investment promotion } \\
\text { policy }(\times 8)\end{array}$ & Investment profile from ICRG & PSR Group \\
\hline & & $\begin{array}{l}\text { Completeness of law and } \\
\text { regulations }(\times 9)\end{array}$ & Law and orders from ICRG & PSR Group \\
\hline & \multirow{3}{*}{$\begin{array}{l}\text { Humanistic } \\
\text { environment }\end{array}$} & $\begin{array}{l}\text { Human development } \\
\qquad(\times 10)\end{array}$ & Human development index & UNDP \\
\hline & & $\begin{array}{l}\text { Cultural communication } \\
\qquad(\times 11)\end{array}$ & $\begin{array}{l}\text { Sum of Confucius Institutes and Confucius } \\
\text { Classrooms in host country }\end{array}$ & $\begin{array}{l}\text { Confucius Institutes Annual } \\
\text { Development Report }\end{array}$ \\
\hline & & $\begin{array}{l}\text { Tourism communication } \\
\qquad(\times 12)\end{array}$ & $\begin{array}{c}\text { Proportion of international tourism revenue in } \\
\text { exports }\end{array}$ & World Bank \\
\hline & \multirow[b]{2}{*}{$\begin{array}{l}\text { Social } \\
\text { environment }\end{array}$} & \multirow{2}{*}{$\begin{array}{l}\text { Technical level }(\times 13) \\
\text { Informatization level } \\
\qquad(\times 14)\end{array}$} & Proportion of high-tech exports in total exports & World Bank \\
\hline & & & Individuals using the internet ( $\%$ of population) & World Bank \\
\hline Output & \multicolumn{2}{|c|}{$\begin{array}{c}\text { China's outward FDI stock in transport by } \\
\text { country and region }\end{array}$} & $\begin{array}{c}\text { China's outward FDI stock by country and region } \\
\text { multiplied by the proportion of transportation/ } \\
\text { storage and postal service }\end{array}$ & $\begin{array}{l}\text { Statistical Bulletin of China's } \\
\text { Outward Foreign Direct } \\
\text { Investment }\end{array}$ \\
\hline
\end{tabular}

TABLE 2: Chinese TII performance along the BRI in 2019.

\begin{tabular}{|c|c|c|c|c|c|}
\hline Region & Country & Score (SBM) & Rank (SBM) & Score (SE-SBM) & Rank (SE-SBM) \\
\hline NA (North Asia) & Mongolia & 0.080708 & 23 & 0.080708 & 23 \\
\hline \multirow{8}{*}{ SEA (Southeast Asia) } & Singapore & 1 & 1 & 4.190005 & 1 \\
\hline & Malaysia & 0.153982 & 19 & 0.153982 & 19 \\
\hline & Indonesia & 1 & 1 & 1.148768 & 3 \\
\hline & Myanmar & 0.338754 & 14 & 0.338754 & 14 \\
\hline & Thailand & 0.1731 & 17 & 0.1731 & 17 \\
\hline & Vietnam & 0.168226 & 18 & 0.168226 & 18 \\
\hline & Brunei & 0.533768 & 11 & 0.533768 & 11 \\
\hline & Philippines & 0.019074 & 30 & 0.019074 & 30 \\
\hline \multirow{4}{*}{ SA (South Asia) } & India & 0.153513 & 20 & 0.153513 & 20 \\
\hline & Pakistan & 1 & 1 & 1.005904 & 7 \\
\hline & Bangladesh & 1 & 1 & 1.035573 & 6 \\
\hline & Sri Lanka & 0.050685 & 25 & 0.050685 & 25 \\
\hline \multirow{13}{*}{ CEE (Central and Eastern Europe) } & Greece & 0.007573 & 34 & 0.007573 & 34 \\
\hline & Poland & 0.01565 & 31 & 0.01565 & 31 \\
\hline & Lithuania & 0.000291 & 46 & 0.000291 & 46 \\
\hline & Estonia & 0.00238 & 41 & 0.00238 & 41 \\
\hline & Latvia & 0.0003 & 45 & 0.0003 & 45 \\
\hline & Czech Republic & 0.006822 & 36 & 0.006822 & 36 \\
\hline & Hungary & 0.01021 & 33 & 0.01021 & 33 \\
\hline & Slovenia & 0.005799 & 37 & 0.005799 & 37 \\
\hline & Croatia & 0.003612 & 40 & 0.003612 & 40 \\
\hline & Serbia & 0.03712 & 27 & 0.03712 & 27 \\
\hline & Albania & 0.001763 & 42 & 0.001763 & 42 \\
\hline & Romania & 0.013076 & 32 & 0.013076 & 32 \\
\hline & Bulgaria & 0.004427 & 39 & 0.004427 & 39 \\
\hline
\end{tabular}


TABLE 2: Continued.

\begin{tabular}{|c|c|c|c|c|c|}
\hline Region & Country & Score (SBM) & Rank (SBM) & Score (SE-SBM) & Rank (SE-SBM) \\
\hline \multirow{7}{*}{ CIS (Commonwealth of Independent States) } & Russia & 0.502234 & 13 & 0.502234 & 13 \\
\hline & Kazakhstan & 0.184492 & 15 & 0.184492 & 15 \\
\hline & Ukraine & 0.005127 & 38 & 0.005127 & 38 \\
\hline & Belarus & 0.026955 & 28 & 0.026955 & 28 \\
\hline & Azerbaijan & 0.000324 & 44 & 0.000324 & 44 \\
\hline & Armenia & 0.000428 & 43 & 0.000428 & 43 \\
\hline & Moldova & 0.000203 & 47 & 0.000203 & 47 \\
\hline \multirow{15}{*}{ WA and NA (Western Asia and North Africa) } & Iran & 1 & 1 & 1.29993 & 2 \\
\hline & Iraq & 1 & 1 & 1.095454 & 5 \\
\hline & Turkey & 0.104654 & 22 & 0.104654 & 22 \\
\hline & Jordan & 0.023669 & 29 & 0.023669 & 29 \\
\hline & Lebanon & 0.000154 & 48 & 0.000154 & 48 \\
\hline & Israel & 0.117436 & 21 & 0.117436 & 21 \\
\hline & Saudi Arabia & 0.514024 & 12 & 0.514024 & 12 \\
\hline & Yemen & 1 & 1 & 1 & 9 \\
\hline & Oman & 0.182816 & 16 & 0.182816 & 16 \\
\hline & United Arab Emirates & 1 & 1 & 1.135861 & 4 \\
\hline & Qatar & 0.617779 & 10 & 0.617779 & 10 \\
\hline & Kuwait & 1 & 1 & 1 & 8 \\
\hline & Bahrain & 0.007154 & 35 & 0.007154 & 35 \\
\hline & Cyprus & 0.037417 & 26 & 0.037417 & 26 \\
\hline & Egypt & 0.073804 & 24 & 0.073804 & 24 \\
\hline
\end{tabular}

TABLE 3: The specific classification results based on the average TII performance.

\begin{tabular}{lr}
\hline Area classification & Country \\
\hline $\begin{array}{l}\text { High-performance area } \\
\text { Medium-performance } \\
\text { area }\end{array}$ & Myanmar, Pakistan, Iran, Indonesia, Iraq, Saudi Arabia, Russia, and Singapore \\
Low-performance area & $\begin{array}{r}\text { Mithuania, Estonia, Armenia, Moldova, Lebanon, Latvia, Slovenia, Croatia, Czech Republic, Bulgaria, Greece, } \\
\text { Jordan, Ukraine, Azerbaijan, Hungary, Belarus, Poland, Bahrain, Albania, Romania, Thailand, Egypt, } \\
\text { Bangladesh, Turkey, Oman, Malaysia, Serbia, Philippines, Cyprus, Sri Lanka, and Israel }\end{array}$ \\
\hline
\end{tabular}

Among the input indicators with the smallest shadow price in these countries, the three input indicators with the largest proportion are $\times 14$ (informatization level), $\times 5$ (economic freedom), and $\times 2$ (political relations with China), respectively. As is shown in Figure 2, the increasing proportion of $\times 14$ indicates that the informatization level of each country is constantly growing, while the influence of this factor on the TII performance along the BRI is continuously decreasing. On the one hand, it reflects the continuous improvement of the global informatization level, which is not quite attractive to Chinese investment. On the other hand, China will also improve the local informatization level by making investments. The number of $\times 5$ gradually decreases, indicating that the impact of economic marketization on TII performance is gradually increasing and that investors are gradually paying attention to the degree of economic marketization in the host country. In addition, diplomatic relations with China also have a small impact on TII performance, which reflects from many aspects that China does not fully value the economic, trade and political relations with China in TII, but intends to help countries along the road to achieve the interconnection between countries.

\section{TII Performance Promotion Measures}

In order to further find out the promotion direction of TII performance in different performance areas, this section will analyze the returns to scale of countries in each investment performance area over the years and explore the promotion path of investment performance while avoiding the potential investment risks.

6.1. Promotion Path in the High-Performance Area. The specific trend of TII performance of countries in the highperformance area from 2011 to 2019 is shown in Figure 3. Except for Singapore, which shows a significant upward trend, and Myanmar, which continues to decline from 2011 to 2019, the investment performance of other countries fluctuates around 1 in a small range.

Table 4 shows the results of return on investment scale in these countries. Chinese TII performance in more than half of the countries remains unchanged in terms of return on investment scale since 2018. That is to say, when the input indicators increase, Chinese TII performance also increases in a certain proportion. In the high-performance area, Chinese TII has accumulated some experience and the range 


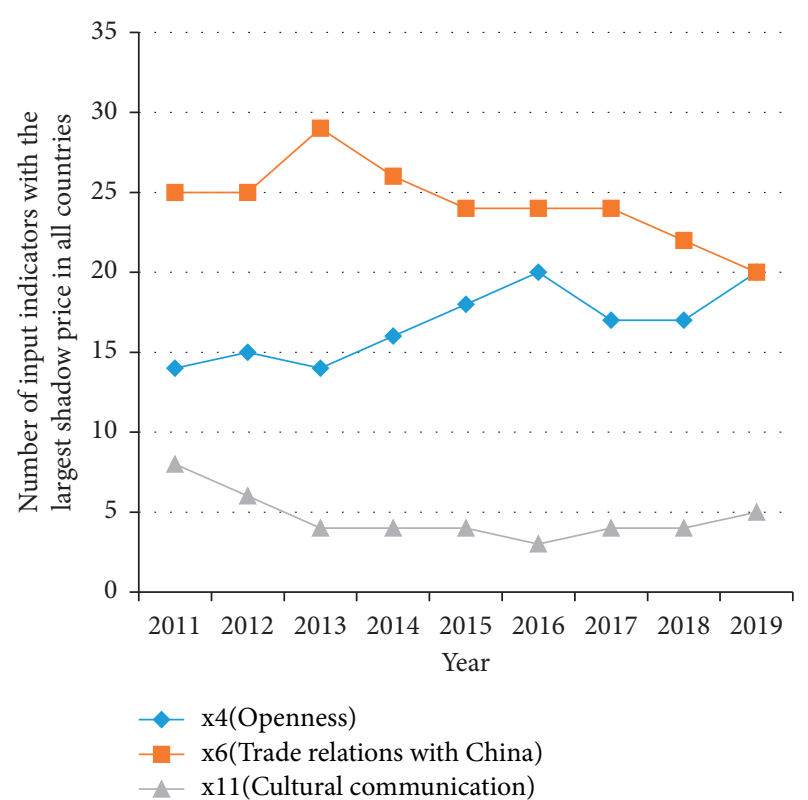

Figure 1: The number of $\times 4, \times 6$, and $\times 11$ as the largest shadow price, respectively.

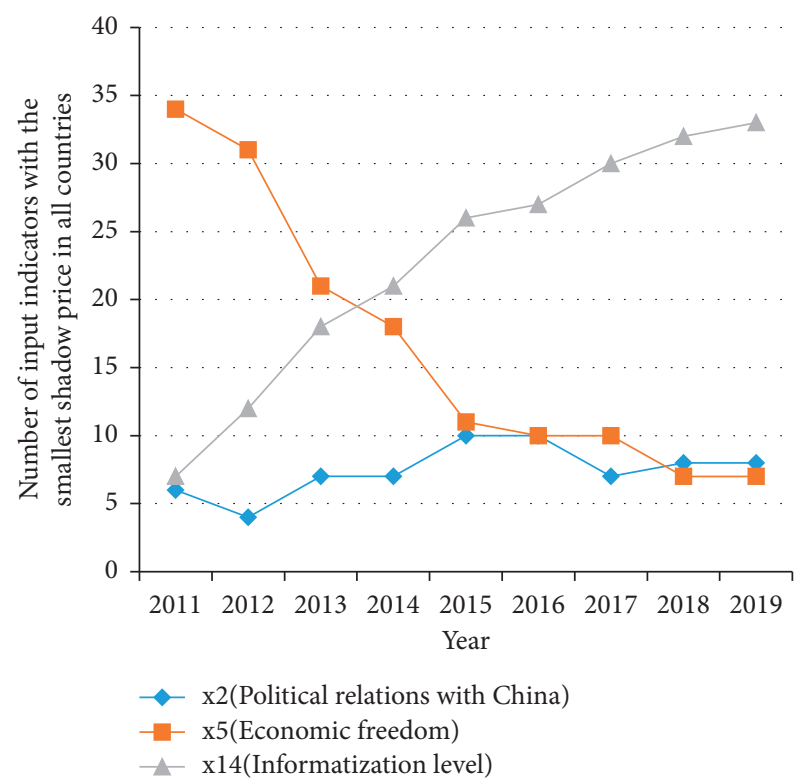

Figure 2: The number of $\times 2, \times 5$, and $\times 14$ as the smallest shadow price, respectively.

of input and output changes is reasonable. It also shows that for these countries, the only way to improve TII performance is to find new sources of investment growth.

To find new sources of investment growth, we mainly analyzed the shadow prices of all elements during the period of 2017-2019. According to the analysis of the top three factors of shadow price, the shadow price of technical level factors in Myanmar, Pakistan, Iran, and Saudi Arabia is relatively high. In order to further improve the performance of Chinese TII in these countries, we could strengthen technical communication with these countries and form more industrial chains of high-tech products. In Indonesia and Russia, the shadow price of the completeness of law and regulations is relatively high, so it needs to be further improved. Due to the limited population and small national area, Singapore needs to make a breakthrough from the human and geographical perspectives and provide more and better labor force. Iraq, troubled by wars, has a positive correlation between military politics and TII performance. When the domestic political situation is stable and there are few military conflicts, it is conducive to TII, but TII performance is low.

The main path to promote TII performance of the countries in high-performance area is to enhance the technology and service communication with countries along the BRI to drive the TII and improve the investment performance. For countries with large shadow price of laws and regulations, opportunity cost could arise if investors are not familiar with related laws and regulations. Therefore, risks associated with investment can be reduced through cooperation with target domestic enterprises rather than direct investment.

6.2. Promotion Path in the Medium-Performance Area. The specific trend of TII performance of countries in the medium-performance area from 2011 to 2019 is shown in Figure 4. And it can be seen that the TII performance of Kuwait and the United Arab Emirates began to be stable after rising in 2015. The TII performance of Kazakhstan, Mongolia, India, Yemen, Qatar, and Brunei fluctuated greatly, while that of other countries fluctuated in a small range.

Chinese TII performance in most countries has been increasing in terms of return on investment scale. Compared with countries in high-performance area, the growth of these indicators will promote the Chinese TII performance, which also shows that appropriate improvement of input indicators could enhance Chinese TII performance. The shadow price of cultural communication in Brunei, Vietnam, Yemen, Qatar, and Kuwait is relatively high, so it is necessary to further improve the cultural communication between China and these countries. Cultural differences can lead to differences in business thinking and communication difficulties. According to statistics, the improper cultural integration is the main reason for the failure of enterprise management. The shadow price of human development in India is relatively high, mainly because of the different levels of labor force and the large number of poor people in India, which affect the performance of Chinese TII in India to a certain extent. Kazakhstan needs to further improve its completeness of laws and regulations, and the United Arab Emirates should improve its technology.

The main path to promote TII performance of the countries in medium-performance area is to promote cultural communication with these countries. Similar or acceptable culture can enable Chinese enterprises to better give play to their comparative advantages, establish a sound relationship network, and obtain convenience in the market. In addition, if some target countries want to improve domestic industrial mobility through transportation 


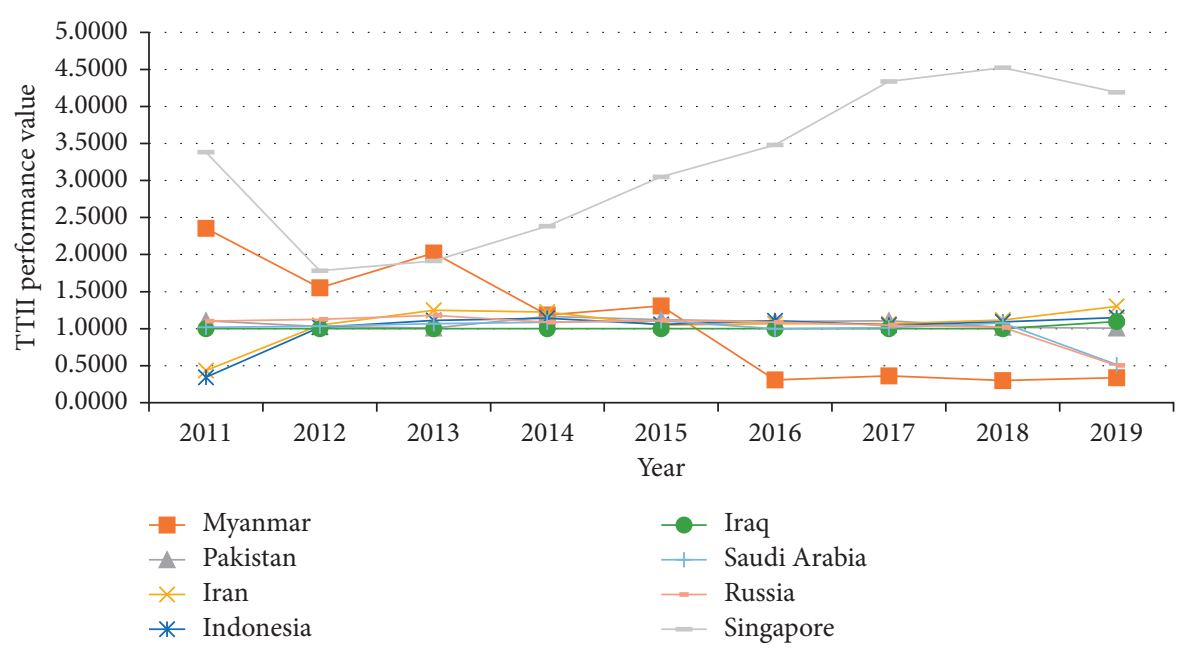

FIgURE 3: Chinese TII performance in the high-performance area from 2011 to 2019.

TABLE 4: Return on scale analysis for countries in the high-performance area from 2011 to 2019.

\begin{tabular}{|c|c|c|c|c|c|c|c|c|c|}
\hline Country in high-performance area & 2011 & 2012 & 2013 & 2014 & 2015 & 2016 & 2017 & 2018 & 2019 \\
\hline Myanmar & - & - & - & + & + & + & + & + & + \\
\hline Pakistan & + & + & + & + & + & - & - & + & - \\
\hline Iran & + & + & - & - & + & + & + & - & - \\
\hline Indonesia & + & + & + & + & + & - & + & - & - \\
\hline Iraq & + & - & + & + & + & + & + & - & - \\
\hline Saudi Arabia & + & + & - & - & - & + & + & - & + \\
\hline Russia & + & + & + & + & - & + & + & + & + \\
\hline Singapore & + & + & + & + & + & + & - & - & - \\
\hline
\end{tabular}

The symbol "+" means the return to scale is increasing and "-" means the return to scale is constant.

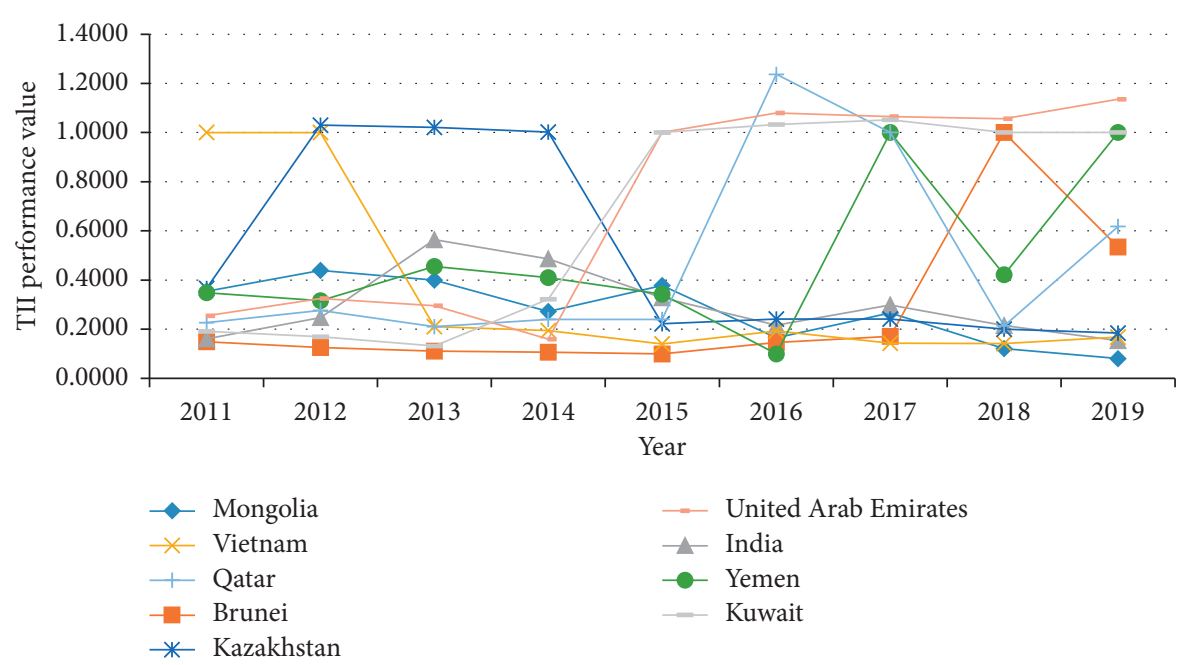

FIGURE 4: Chinese TII performance in the medium-performance area from 2011 to 2019.

infrastructure, they will need to provide higher-quality labor in order to attract external investment.

6.3. Promotion Path in the Low-Performance Area. The specific trend of TII performance of countries in the lowperformance area from 2011 to 2019 is shown in Figure 5.
The TII performance of most countries was relatively stable, with Bangladesh and Serbia seeing significant changes in 2018 and 2019.

The results of return on investment scale show that Chinese TII performance has been increasing in all countries. Similarly, appropriate promotion in input indicators is of great importance. And these countries have a more urgent 


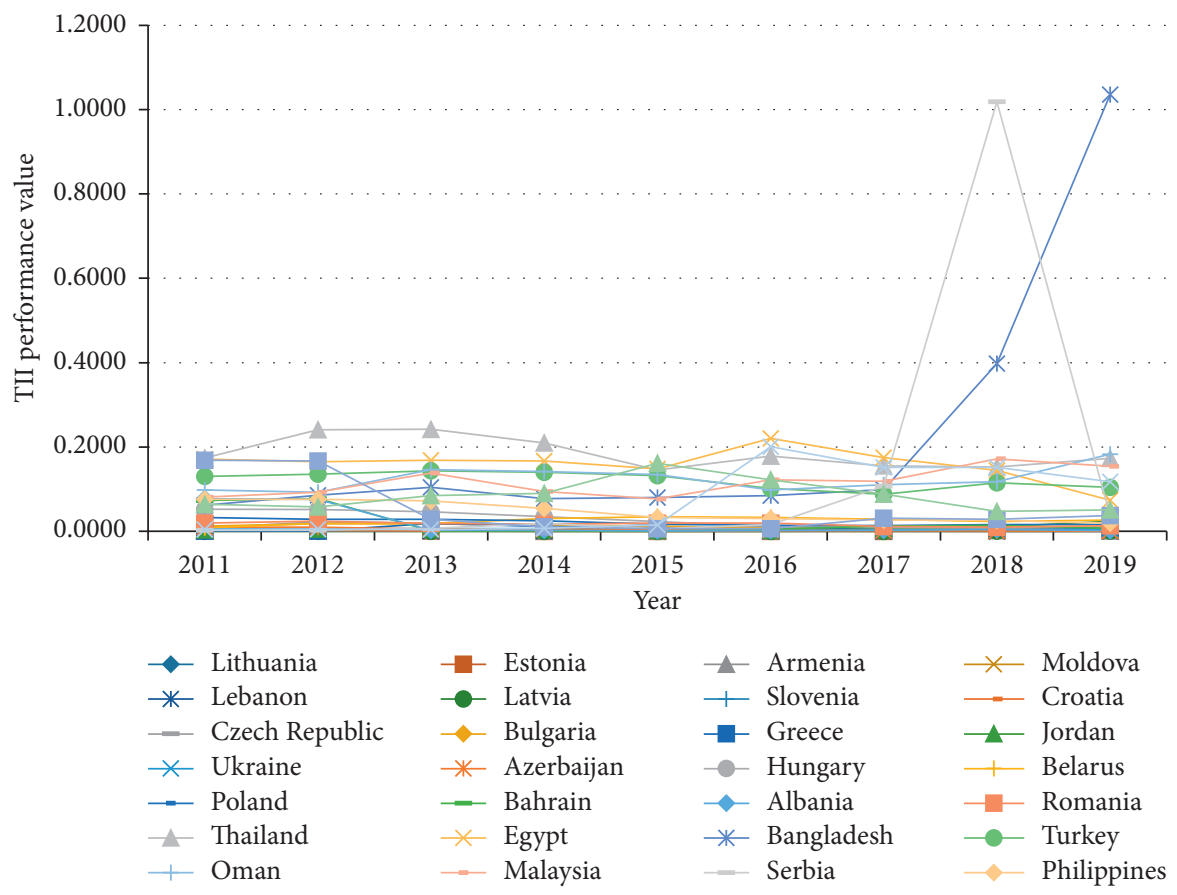

FIgURE 5: Chinese TII performance in the low-performance area from 2011 to 2019.

need for input indicator promotion than countries in medium-performance area.

There are many countries in low-performance area, and the indicators of high shadow price corresponding countries mainly include $\times 11$ (Lithuania, Estonia, Moldova, Lebanon, Croatia, Czech Republic, Greece, Azerbaijan, Oman, Malaysia, and Cyprus), $\times 1$ and $\times 3$ (Latvia, Belarus, Thailand, Egypt, Turkey, Philippines, and Israel), $\times 9$ (Armenia, Slovenia, Bulgaria, Hungary, Poland, Romania, and Malaysia), $\times 12$ (Ukraine and Bangladesh), and $\times 13$ (Jordan, Bahrain, Albania, Egypt, Bangladesh, Serbia, and Sri Lanka).

Based on the above analysis of countries in low-performance area, we give the following measures for promoting TII performance:

(1) For most of the countries in central and eastern Europe, the cultural, institutional, and geographic distances make the trade connection between these countries and China not high. In the future, cultural, economic, and political exchanges between countries can be increased, so that the economic, institutional, and cultural distances between countries can be gradually reduced. In this way, the potential risks in overseas investment and operation can be reduced.

(2) For countries with high shadow price of political and military stability such as Latvia, Belarus, Thailand, Egypt, Turkey, Philippines, and Israel, the premise of Chinese TII in these countries is to minimize political risk.

(3) The shadow price of the completeness of law and regulations of Armenia, Slovakia, Bulgaria, Hungary, Poland, Romania, and Malaysia is relatively high. Similarly, cooperation with target domestic enterprises instead of direct investment can be adopted to reduce the risks associated with investment.

(4) Jordan, Bahrain, Albania, Egypt, Bangladesh, Serbia, and Sri Lanka have relatively high shadow price in technical level. So, China's advantages in manufacturing and automation technology should be utilized to provide them with technical assistance and assist target countries to do well in their domestic competitive industries. The improvement of technical level will promote the continuous accumulation of industrial scale and stimulate their foreign trade.

(5) The shadow price of some countries in tourism communication is relatively high, so they can develop their own tourism industry to a certain extent.

\section{Conclusion and Implications}

TII occupies a very important position in regional development policy [24]. In the competition for foreign direct investment inflow, developing countries try to improve their investment environment by updating policies. Enterprises in these countries or regions wish to improve production efficiency, and they will promote the development of complex transportation systems to make them more competitive [48]. Under the background of BRI, TII will bring prosperity to target country. For investors, they will also face additional risks while obtaining economic benefits. Therefore, this paper aims to study how Chinese enterprises can improve TII performance, reduce investment risks, and better promote the connectivity of countries along the BRI. 
The research contributions of this paper are mainly in two aspects. On the one hand, this paper used the SE-SBM theory to construct a linear programming model for the performance evaluation of TII and selected the target countries along the BRI as the empirical objects. On the other hand, this paper used cluster analysis to classify the performance of Chinese TII and put forward the promotion path of various performance areas by combining returns to scale and shadow prices of input indicators. This paper mainly draws the following conclusions:

(1) The openness of the target country can improve TII performance more than the trade links with China. It indicates that Chinese TII in countries along the BRI is more concerned with the openness of the target country.

(2) As for input indicators with the lowest shadow price, the proportion of economic freedom becomes smaller, which indicates that the effect of economic marketization on the improvement of TII performance has been gradually paid attention to. And the informatization level of the target country has no effect on the performance.

(3) Chinese TII performance in most countries of highperformance area remains unchanged in terms of return on investment scale since 2018. Technical level is the most important factor affecting performance. Therefore, frequent technology and service communication is essential.

(4) Chinese TII performance in most countries of medium-performance area has been increasing in terms of return on investment scale. Cultural communication is a key factor affecting performance. Therefore, it is essential to promote cultural communication with these countries and help reduce investment and operation risks of enterprises caused by different cultural backgrounds.

(5) Chinese TII performance in most countries of lowperformance area has been increasing. Political and military stability has become the key factor affecting TII performance in some countries. In general, countries in low-performance area need to make improvements in cultural communication, political and military stability, laws and regulations, and technology and tourism communication, respectively.

There are, however, still limitations in this paper. The selection of the evaluation system is not perfect enough, and some indicators are not taken into account due to the lack of data. Moreover, the quantification of some indicators may lead to certain deviations in the results, such as investment promotion policy $(\times 8)$ and cultural communication $(\times 11)$. We used investment profile data from ICRG to reflect $\times 8$, which cannot fully reflect the promotion policies of transport infrastructure investment. We used "sum of Confucius Institutes and Confucius Classrooms in host country" to reflect cultural communication but it was insufficient. In fact, it might be better to use student exchange as an indicator. But there is no authoritative statistical source. These need to be further improved. In addition, our future research will focus on combining the policies of various countries to study the location selection of Chinese overseas transport infrastructure investment.

\section{Data Availability}

The data in this paper are freely available from the data sources noted in this paper.

\section{Conflicts of Interest}

The authors declare that they have no conflicts of interest regarding the publication of this paper.

\section{Acknowledgments}

This study was funded by the Major Project of National Social Science Fund of China (Grant no. 20\&ZD070).

\section{References}

[1] B. Kristian, "International integration and regional inequalities: how important is national infrastructure?" The Manchester School, vol. 79, no. 5, pp. 952-971, 2011.

[2] B. Hoekman and A. Nicita, "Trade policy, trade costs, and developing country trade," World Development, vol. 39, no. 12, pp. 2069-2079, 2011.

[3] F. de Soyres, A. Mulabdic, S. Murray, N. Rocha, and M. Ruta, "How much will the belt and road initiative reduce trade costs?” International Economics, vol. 159, pp. 151-164, 2019.

[4] M. Islam, "The year of the pig. Can China's belt and road initiative save the world from a mud fight?" Euler Hermes Economic Research, 2019, https://www.eulerhermes.com/en global/news-insights/economic-insights/Year-of-the-pig-CanChina-s-Belt-and-Road-Initiative-save-the-world-from-amud-fight.html.

[5] N. Zhou, Q. Wu, X. Hu, D. Xu, and X. Wang, "Evaluation of Chinese natural gas investment along the Belt and Road Initiative using super slacks-based measurement of efficiency method," Resources Policy, vol. 67, Article ID 101668, 2020.

[6] J. Du and Y. Zhang, "Does One Belt One Road initiative promote Chinese overseas direct investment?" China Economic Review, vol. 47, pp. 189-205, 2018.

[7] D. Roland-Holst, "Infrastructure as a catalyst for regional integration, growth, and economic convergence: scenario analysis for Asia," in From Growth to Convergence, F. Zhai, Ed., Palgrave Macmillan, London, UK, 2009.

[8] O. Lorz, "Investment in trade facilitating infrastructure: a political-economy analysis," European Journal of Political Economy, vol. 65, Article ID 101928, 2020.

[9] P. Krugman and A. J. Venables, "Integration, specialization, and adjustment," European Economic Review, vol. 40, no. 3-5, pp. 959-967, 1993.

[10] R. P. Pradhan, N. R. Norman, Y. Badir, and B. Samadhan, "Transport infrastructure, foreign direct investment and economic growth interactions in India: the ARDL bounds testing approach," Procedia-Social and Behavioral Sciences, vol. 104, no. 1, pp. 914-921, 2013.

[11] R. Anas, O. Z. Tamin, and S. S. Wibowo, "Applying inputoutput model to estimate the broader economic benefits of cipularang tollroad investment to bandung district," Procedia Engineering, vol. 125, pp. 489-497, 2015. 
[12] H. Xu, "Domestic railroad infrastructure and exports: evidence from the silk route," China Economic Review, vol. 41, pp. 129-147, 2016.

[13] G. Yang, X. Huang, J. Huang, and H. Chen, "Assessment of the effects of infrastructure investment under the belt and road initiative," China Economic Review, vol. 60, Article ID 101418, 2020.

[14] G. M. Ahlfeldt and A. Feddersen, "From periphery to core: measuring agglomeration effects using high-speed rail," Journal of Economic Geography, vol. 18, no. 2, pp. 355-390, 2018.

[15] C. Wang, W. Meng, and X. Hou, “The impact of high-speed rails on urban economy: an investigation using night lighting data of Chinese cities," Research in Transportation Economics, vol. 80, Article ID 100819, 2020.

[16] R. Tan, K. Liu, and B. Lin, "Transportation infrastructure development and China's energy intensive industries - a road development perspective," Energy, vol. 149, pp. 587-596, 2018.

[17] J. Ji, Z. Zou, and Y. Tian, "Energy and economic impacts of China's 2016 economic investment plan for transport infrastructure construction: an input-output path analysis," Journal of Cleaner Production, vol. 238, Article ID 117761, 2019.

[18] T. F. Halaszovich and A. Kinra, "The impact of distance, national transportation systems and logistics performance on FDI and international trade patterns: results from Asian global value chains," Transport Policy, vol. 98, pp. 35-47, 2020.

[19] S. A. Rehman Khan, D. Qianli, W. SongBo, K. Zaman, and Y. Zhang, "Travel and tourism competitiveness index: the impact of air transportation, railways transportation, travel and transport services on international inbound and outbound tourism," Journal of Air Transport Management, vol. 58, pp. 125-134, 2017.

[20] I. Kolstad and A. Wiig, "What determines Chinese outward FDI?" Journal of World Business, vol. 47, no. 1, pp. 26-34, 2012.

[21] T. Yin, L. D. Propris, and L. Jabbour, "Assessing the effects of policies on China's outward foreign direct investment," International Business Review, Article ID 101818, 2021, In press.

[22] A. P. Kyriacou, L. Muinelo-Gallo, and O. Roca-Sagalés, "Construction corrupts: empirical evidence from a panel of 42 countries," Public Choice, vol. 165, no. 1-2, pp. 123-145, 2015.

[23] F. Grigoli and Z. Mills, "Institutions and public investment: an empirical analysis," Economics of Governance, vol. 15, no. 2, pp. 131-153, 2014.

[24] R. Crescenzi, M. D. Cataldo, and A. Rodriguez-Pose, "Government quality and the economic returns of transport infrastructure investment in European regions," Journal of Regional Science, vol. 56, no. 4, pp. 553-582, 2016.

[25] V. Fisch-Romito and C. Guivarch, "Transportation infrastructures in a low carbon world: an evaluation of investment needs and their determinants," Transportation Research Part D: Transport and Environment, vol. 72, pp. 203-219, 2019.

[26] A. P. Kyriacou, L. Muinelo-Gallo, and O. Roca-Sagalés, "The efficiency of transport infrastructure investment and the role of government quality: an empirical analysis," Transport Policy, vol. 74, pp. 93-102, 2019.

[27] D. Marchetti and P. Wanke, "Brazil's rail freight transport: efficiency analysis using two-stage DEA and cluster-driven public policies," Socio-Economic Planning Sciences, vol. 59, pp. 26-42, 2017.

[28] H. Y. Liu, Y. K. Tang, X. L. Chen, and J. Poznanska, "The determinants of Chinese outward FDI in countries along "one belt one road"' Emerging Markets Finance and Trade, vol. 53, no. 6, pp. 1374-1387, 2017.

[29] W. $\mathrm{Zu}$ and $\mathrm{H}$. Liu, "Exchange rate movements, political environment and Chinese outward FDI in countries along "One Belt One Road"” in Proceedings of the International Conference on Management Science and Engineering Management, August 2017.

[30] Y. Chen, Y. Chao, W. Liu, K. Tao, and P. Lian, "Make friends, not money: how Chinese enterprises select transport infrastructure investment locations along the Belt and Road," Transport Policy, vol. 101, pp. 119-132, 2021.

[31] K. Tone, "A slacks-based measure of super-efficiency in data envelopment analysis," European Journal of Operational Research, vol. 143, no. 1, pp. 32-41, 2002.

[32] J. Li, K. E. Meyer, H. Zhang, and Y. Ding, "Diplomatic and corporate networks: bridges to foreign locations," Journal of International Business Studies, vol. 49, no. 12, pp. 1-25, 2017.

[33] L. Luo, Z. Qi, and P. Hubbard, "Not looking for trouble: understanding large-scale Chinese overseas investment by sector and ownership," China Economic Review, vol. 46, pp. 142-164, 2017.

[34] D. Hudson and D. Lee, "The old and new significance of political economy in diplomacy," Review of International Studies, vol. 30, no. 3, pp. 343-360, 2004.

[35] S. J. V. Moons and P. A. G. van Bergeijk, "Does economic diplomacy work? A meta-analysis of its impact on trade and investment," The World Economy, vol. 40, no. 2, pp. 336-368, 2017.

[36] B. Gawellek, J. Lyu, and B. Süssmuth, "Geo-politics and the impact of China's outward investment on developing countries: evidence from the great recession," Emerging Markets Review, Article ID 100815, 2021, In press.

[37] H. Ma, Z. Sun, and C. Fang, "Risk assessment of transnational oil investment in Central Asia using a fuzzy comprehensive evaluation method," Regional Sustainability, vol. 1, no. 1, pp. 11-19, 2020.

[38] S. Cheng and S. Qi, “The potential for China's outward foreign direct investment and its determinants: a comparative study of carbon-intensive and non-carbon-intensive sectors along the Belt and Road," Journal of Environmental Management, vol. 282, Article ID 111960, 2021.

[39] J. Wessel, "Evaluating the transport-mode-specific trade effects of different transport infrastructure types," Transport Policy, vol. 78, pp. 42-57, 2019.

[40] A. Bottasso, M. Conti, P. C. de Sa Porto, C. Ferrari, and A. Tei, "Port infrastructures and trade: empirical evidence from Brazil," Transportation Research Part A: Policy and Practice, vol. 107, pp. 126-139, 2018.

[41] B. Kirkpatrick, D. Parker, and Y. F. Zhang, "Foreign direct investment in infrastructure in developing countries: does regulation make a difference?" Transnational Corporations, vol. 15, no. 1, pp. 143-171, 2004.

[42] M. I. Al Irsyad, A. Halog, and R. Nepal, "Estimating the impacts of financing support policies towards photovoltaic market in Indonesia: a social-energy-economy-environment model simulation," Journal of Environmental Management, vol. 230, pp. 464-473, 2019.

[43] A. Y. Lin, "Law, culture and investment performance: a crosscountry analysis," Global Finance Journal, vol. 19, no. 3, pp. 323-341, 2009.

[44] G. Feng and X. Mu, "Cultural challenges to Chinese oil companies in Africa and their strategies," Energy Policy, vol. 38, no. 11, pp. 7250-7256, 2010. 
[45] J. Li, B. Liu, and G. Qian, "The belt and road initiative, cultural friction and ethnicity: their effects on the export performance of SMEs in China," Journal of World Business, vol. 54, no. 4, pp. 350-359, 2019.

[46] D. Quer, L. Rienda, and R. Andreu, "Establishment mode choice by Chinese firms in Latin America: the role of host country-specific experience and government official visits," Thunderbird International Business Review, vol. 62, no. 1, pp. 49-63, 2020.

[47] J. Chen, Y. Liu, and W. Liu, "Investment facilitation and China's outward foreign direct investment along the belt and road," China Economic Review, vol. 61, Article ID 101458, 2020.

[48] S. Saidi, V. Mani, H. Mefteh, M. Shahbaz, and P. Akhtar, "Dynamic linkages between transport, logistics, foreign direct Investment, and economic growth: empirical evidence from developing countries," Transportation Research Part A: Policy and Practice, vol. 141, pp. 277-293, 2020. 